\title{
PRECIPITATION OF SALTS IN MASONRY MAPPED WITH GEORADAR
}

\author{
Frank Andreasen \\ Dansk Geoservice, Helleskraenten 29, DK-2860 Soeborg, Denmark \\ Present address: \\ Department of Geology and Geotechnical Engineering, \\ Technical University of Denmark, DK-2800 Lyngby
}

\section{INTRODUCTION}

The church at the Christiansborg castle in Copenhagen suffered from a major fire in 1992. The fire was caused by a small emergency flare fired from a boat in the harbour during the local carnival. During the reconstruction of the church an ornamental marble-like mortar used on the inside walls became miscoloured apparently because of a too high water content in the thick masonry. As it turned out to be impossible to completely dry out the part of the walls closest to the ground it was decided to perform a georadar survey to map the distribution of water in the walls and to determine wether the water originated from the fire hoses or from the surrounding soil. Prior to the radar survey the water content in the walls was monitored during more than a year using a Troxler equipment. As determined by calibrated Troxler values the water content in the "dry" zone was between 1 and $3.5 \%$ and between 6 and $12 \%$ in the wet zone (weight percent).

\section{APPLIED TECHNIQUES}

The main factor controlling the velocity of radio waves in porous solid media is the content of water versus air, therefore the georadar technique (GPR) is an excellent method to determine variations in the water content. The wall-pillars investigated were massive brickwalls with a regular thickness, it was therefore expected to be an easy task to determine variations in the water content as shown in Kahle (1993).

The equipment applied was a SIR-10 impulse radar from GSSI with a thermal plotter, a 500 and a $900 \mathrm{MHz}$ antenna. Data were printed on location and stored on tape for postprocessing. The up to 2.30 metres thick masonry was examined by making continuos profiles from floor level to 2 metres above the floor. A total of 48 vertical profiles representing 8 pillars (outer and inner walls) were measured in two days. The outer pillars were measured on the three inside walls and the inner pillars on all four sides. The initial tests showed good penetration both with the $500 \mathrm{MHz}$ and the $900 \mathrm{MHz}$ antenna.

\section{SURVEY RESULTS}

Figure 1 shows a typical vertical georadar profile representing 2 metres of a brick-wall. The transition from dry masonry to wet high-attenuation masonry is marked with a solid line. From the figure the following observations are done:

- there is a constant apparent thickness of the wall until approaching the transition zone,

- there is a slight increase in apparent thickness of the wall ( $\sim$ increase in $\varepsilon_{\mathrm{v}}$ ) approaching the transition zone,

- there is no penetration through the transition zone in the lower part of the wall,

- there is no reflection from the transition zone. 
The location of the transition zones were mapped with respect to there position above the floor level and with respect to the approximate depth below the wall surfaces. The purpose was to obtain a three dimensional picture of the transition zones separating dry masonry from wet masonry in each wall-pillar. The result of the mapping was a general picture showing the transition zones as dome-shaped structures with contact to the surface of the walls close to the floor, and with an upward increase in distance between the transition zones and the surface of the walls. The apex of the transition zones are located at varying levels above the floor highest in the outer wall-pillars and lowest in the inner wall-pillars.

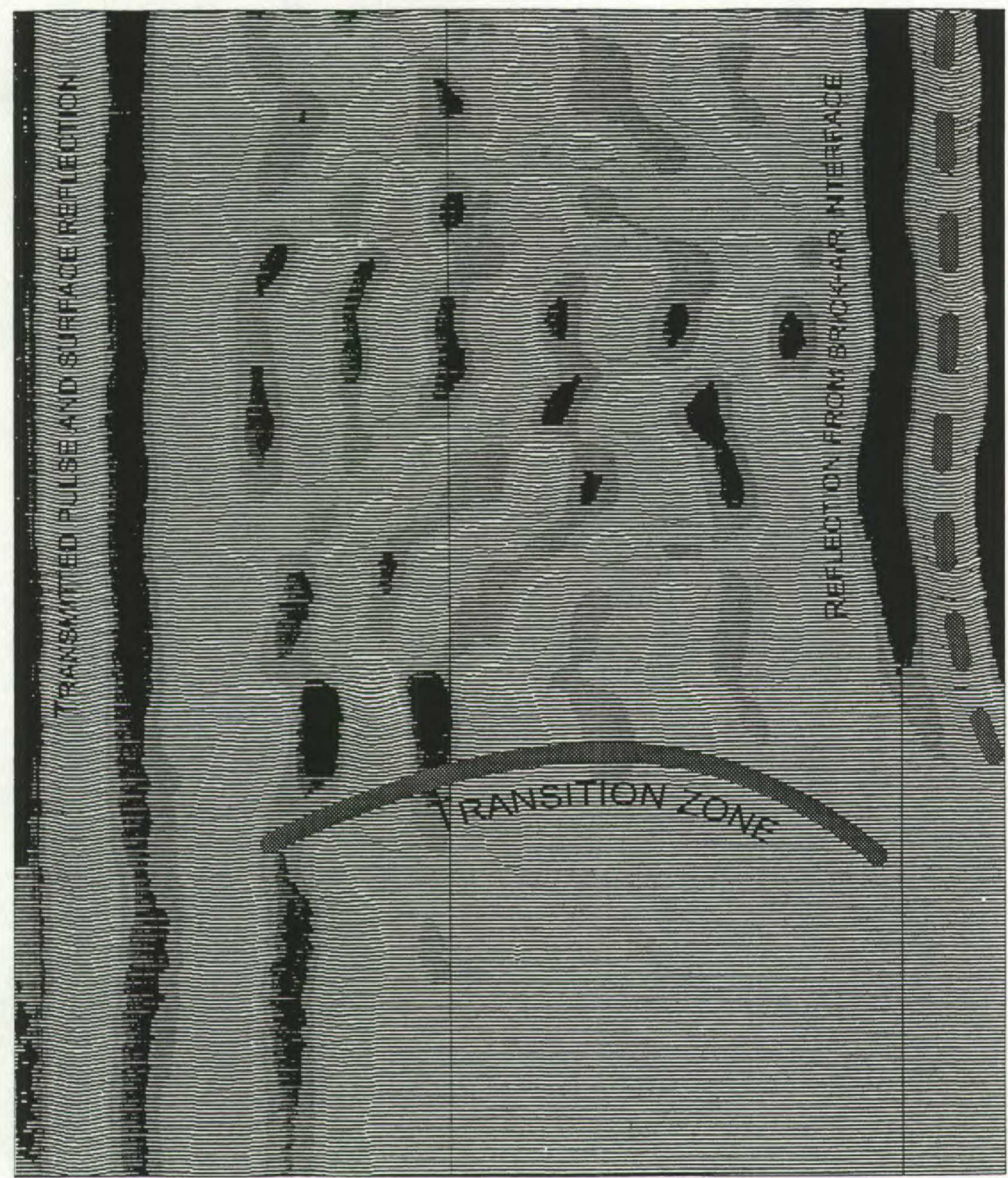

Figure 1. The radargram shows a vertical section through a massive masonry wall-pillar with plane vertical sides. The reflector to the left is a combination of the transmitted pulse and the surface reflection. The reflection in the right side of the figure is from the wall-air interface on the opposite side of the wall. It is seen that the wall in the lower part near the floor is not transparent to the radar due to a very high attenuation of the radar waves. The transition zone is seen from one side only. The radargram recorded along the other side of the wall shows the other side of the transition zone. Above this zone there is a slight increase in the two-way-time. Notice that the transition zone does not result in a reflection. 
The presence of the dome shaped transition zones in the pillars, the increase in two-waytime approaching the transition zones and the lack of penetration through the transition zones is best explained as a result of the presence of water saturated with dissolved salts. The lack of reflections from the transition zones are interpreted as a result of a gradual increase in the water content, and as a result of attenuation of the signal due to the high conductivity caused by dissolved salts.

A fairly accurate velocity estimate of the dry masonry was obtained by recording with an antenna placed in contact with the wall and by moving a metal reflector on the opposite side. The velocity was determined to be $0.16 \mathrm{~m} / \mathrm{ns}$ corresponding to an $\varepsilon_{\mathrm{r}}$ value of 3.6 or a to-way-time of $12.6 \mathrm{~ns} / \mathrm{m}$. An example of a radargram used to determine the two-way time in the dry masonry by means of the reflector technique is shown in Figure 2.

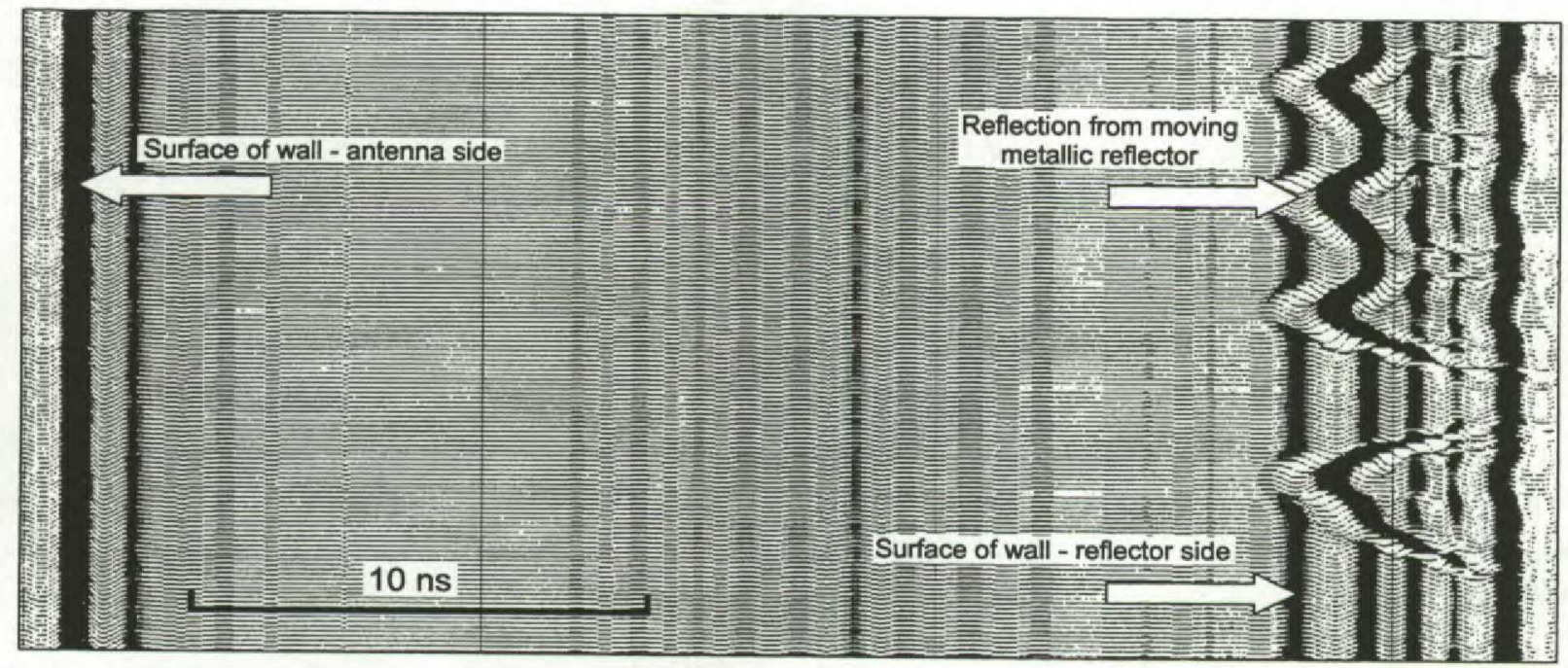

Figure 2. Radargram recorded with a $900 \mathrm{MHz}$ antenna fixed to the wall-surface (left) while shooting towards a moving metal reflector on the other side of the wall (the vertical scale can therefore be regarded as a time-scale). The wall is a massive brick-wall, which at this place has a thickness of $2.20 \mathrm{~m}$. An unmistakable recognition of the reflector from the opposite side of a wall is obtained by using this technique. Notice the inversion of phase in the signal returned from the reflector. In case of a strong attenuation of the signal it is often possible to obtain a good velocity estimate by applying on-line background removal and a very high gain. The reflector technique is convenient for velocity determinations also under other circumstances.

\section{DISCUSSION}

The lack of penetration close to the floor is explained as an attenuation of the radio signal and by assuming the presence of conductive material in the wall. The lack of a reflection from the transition zone is explained by assuming a gradual transition from areas of good penetration and a low content of water to areas of no penetration and a higher content of water with salts in solution. It is known that the percentage of water in the masonry is variable, but no data were available from the transition zone with respect to the amount of water or the distribution of salt across the transition zone, therefore no definitive conclusions can be made regarding the interaction between the radar signal and the transition zone. The highest concentration of salt in solution and the highest concentration of precipitated salts would be expected at the water-air interface and a gradual decrease in the concentration of salt would be expected downwards and towards the centre of the wall. At an abrupt transition from dry masonry to wet conductive masonry one would expect a strong reflection due to a large difference in permittivity. Obviously this is not the case, the transition must therefore be gradual. As seen in Figure 1 there is an increase in two-way-time approaching the transition zone. This is explained by assuming a gradual increase in water content in the bricks. If the 
zone of transition from dry $(\sim 2 \%)$ to wet masonry $(\sim 12 \%)$ is wide compared to the wavelength of the applied antenna no reflection occurs.

From mapping of sedimentary deposits with more low frequency antennas it is known, that the ground water table in a coarse grained well sorted material causes a strong reflection, whereas in a less well sorted and more fine grained material, where capillary forces are active, the ground water table does not result in a visible reflection. The analogy therefore seems reasonable when compared to the transition zone between dry and wet masonry, however, the increase in conductivity leading to attenuation probably also contributes to the lack of a visible reflection.

The transition zone was found to lie at different levels in the outer walls and in the inner walls. In the lowermost $30-40 \mathrm{~cm}$ of the walls there was no penetration at all, above this level there was a gradual but slow increase in depth of penetration, but there was no penetration to the opposite wall until reaching a level of $80-140 \mathrm{~cm}$ above the floor, with the high values in the outer pillars and the lower values in the inner pillars. The reason why the transition zone is lower in the inner pillars is that they are smaller, and that evaporation can take place from all four sides.

\section{CONCLUSIONS}

It was concluded that the problems with the ornamental mortar was caused by the wet brick-wall and by precipitation of salts, further it was concluded that the remaining water in the walls comes from the surrounding soil and not from the fire hoses. The precipitated salts in the walls is a result of many years of capillary transport of water through the walls with salts in solution followed by evaporation of water from within the walls and from the wall surfaces inside the church. The phenomena are well known from other old buildings without concrete foundations.

The salts are dissolved from the mortar and the bricks, but it seems likely that it also comes from the surrounding soil. The church is located only a few tens of metres from the harbour front, and it is originally build on soil dumped in the harbour area of the Middle Age Copenhagen, the soil therefore probably contains some residual seawater. Today the surroundings to the church are more or less paved with concrete, therefore relatively little rainwater infiltrates the soil. This, and draining from cellars and low-lying sewers causes infiltration of seawater. Finally, the evapo-transpiration is accelerated because the church nowadays is heated causing stronger evaporation from the walls.

\section{APPLICATION OF SURVEY RESULTS}

To avoid future problems with the mortar caused by precipitating salts, the cellar under the church floor was excavated so that air from the main church hall could be circulated through the cellar. The evaporation which causes the precipitation of salts in the walls is in this way moved to the cellar. By knowing the mechanisms involved and by using the known levels of the interface between salts in solution and the dry masonry, as determined with the radar, a similar surface area was established and used to dry out the walls in the cellar.

\section{REFERENCES}

Kahle, M. (1993): Investigation of historic masonry by means of radar. IABSE Symposium, Rome 1993, pp.205-212. 